\title{
Review
}

\section{Cloud ethics: Algorithms and the attributes of ourselves and others}

\author{
Louise Amoore \\ Duke University Press, Durham, 2020, xiv+218pp., ISBN 978-1478008316
}

Contemporary Political Theory (2022) 21, S118-S121. https://doi.org/10.1057/s41296021-00465-1; published online 10 May 2021

This ambitious work is a rich and complex response to the ascent of machinelearning algorithms. More specifically, it is an effort to examine the philosophically sophisticated nature of this rising power. It hardly needs to be said that the work is timely, as computational algorithms occupy increasingly central positions not only in the economies of production and distribution but also in the economies of information, a function that extends to the management of social life in general and to the exercise of state security, surveillance, and policing powers in particular. Amoore's exposition begins, in fact, with a quietly harrowing account of the partnership between Geofeedia, a 'location-based analytics platform,' and the Baltimore Police Department during the period following the death of Freddie Gray, a young black man who suffered fatal injuries while in police custody in 2015. In the civil unrest that followed, 'terabytes of images, video, audio, text, and biometric and geospatial data from the protests of the people of Baltimore were rendered as inputs to the deep learning algorithms' (p. 3). Many protesters were arrested or detained without charges based solely on the presumed authority of the predictive algorithm, which had 'learned how to recognize what a protest is, what a gathering of people in the city might mean' (pp. 3-4).

The book is organized in three main sections, preceded by an introduction in which the author sets out her approach to the ethicopolitics of algorithms and distinguishes it from more familiar public calls for vigilance: calls to divest algorithms of their racial biases, for example, or to make them more transparent so that those responsible for their creation can be held accountable. While Amoore recognizes the palpable threats against persons and against rights identified in these calls for action, she seeks to identify effects working at a more fundamental and esoteric level. 'In short,' she writes, 'what matters is not primarily the identification and regulation of algorithmic wrongs, but more significantly how algorithms are implicated in new regimes of verification, new forms of identifying a wrong or of truth telling in the world' (pp. 5-6).

(C) 2021 The Author(s), under exclusive licence to Springer Nature Limited. 1470-8914 Contemporary Political Theory Vol. 21, S3, S118-S121

www.palgrave.com/journals 
Rather than scrutinize algorithms by a framework of moral or political norms, Amoore aims to show how the algorithmic operations themselves have altered and will continue to alter the basic terms and conditions under which any such framework must be considered. Amoore sets out 'a speculative strategy for reinstating the partial, contingent, and incomplete character of all forms of algorithmic forms of calculation' (p. 21). In this strategy of reinstatement, there is already an implicit charge against the aura of omniscience afforded to an impossibly idealized machine-learning algorithm that traffics in impartial, categorical, and complete knowledge immaculately born from raw data. Amoore successfully argues that the reality is far stranger than this. She deftly draws ideas and evidence from a broad range of sources in philosophy, literary theory, cultural studies, and physics to express the stealthy mechanisms by which 'machinelearning algorithms that anticipate our future propensities are seriously threatening the chances that we have to make possible alternative political futures' ( $\mathrm{p}$. xi). This occlusion or stunting of possibilities is not a simple thing. Amoore's critical analysis and her consternation largely turn on a sustained examination of this 'double political foreclosure' (p. 20).

First, a multiplicity of potentials is condensed into a single output, into the actionable resolution of civil, political, and military crises such as volatile street protests, unauthorized border crossings, targeted assassinations, and so on. Understood simplistically, this cannot be a very serious concern, since any decision presupposes a scission like this, in which a field of possibilities is cut away and left behind in the act of decision. There must be more to it, and there is. In a brief treatment of cybernetics for example, Amoore revisits some observations by Michel Foucault and Jacques Derrida on the relation between madness and reason in order to proffer a fascinating historical argument that 'the history of algorithmic rationality is not separable from genealogies of madness.' It is time to think difficult thoughts,' she adds, 'algorithms are always already unreasonable.' Amoore associates the irrationality of algorithms especially with the monomania that is their raison d'etre. For her, the most dismaying aspect of the algorithmic decision is not merely its reductionism but its ostensible erasure of the madness inherent in all decisions. 'The madness of the decision is disavowed by the single output of the algorithm, and this disavowal is a potential horror and a danger' (p. 112). Here and throughout the work there are some daring intellectual arabesques, which may irk some readers who favor a certain kind of analytic rigor, but Amoore convincingly argues that machine-learning algorithms are both metaphysically and epistemically strange in ways that demand careful scrutiny and new modes of thought.

There is a second and arguably more sophisticated claim of foreclosure. It is not simply that machine-learning algorithms condense a multiplicity of potential futures into a single output or forecast. The very process of aggregation that enables this condensation operates on a field of attributes wholly subordinate to the instrumental rationality of the algorithm. It would be easy to mistake this second

(C) 2021 The Author(s), under exclusive licence to Springer Nature Limited. 1470-8914 Contemporary $\quad$ S119 Political Theory Vol. 21, S3, S118-S121 
foreclosure for the simple criticism that algorithms operate narrowly on an incomplete data set, processing a miniaturized salience landscape through what is sometimes picturesquely called the soda straw effect. This is not the issue. Instead, Amoore argues, because of their metaphysical and epistemic strangeness

machine-learning algorithms embody a regime of recognition that identifies what or who matters to the event. Machine-learning algorithms do not merely recognize people and things in the sense of identifying - faces, threats, vehicles, animals, languages - they actively generate recognizability as such, so that they decide what or who is recognizable as a target of interest in an occluded landscape (p. 69).

So this second foreclosure is problematic, not because it operates on a narrow field of data, but because it operates on an alien, or, better still, on an alienated field of attributes, "producing modes of recognition, valuation, and probabilistic decision weighting that are profoundly political and yet do not reside wholly in a recognizable human who writes the rule' (p. 69). This estrangement of human individual and social attributes occurs most dramatically in unsupervised learning algorithms, which are set loose like thousand-eyed seers among colossal stocks and flows of information - information that is not merely digital but also corporeal, geospatial, biometric, and so on - in order to determine on their own the variables, formulations, valuations, and weightings that matter. These are not models that fit to the data; they are models that fit from the data. Indeed, they cannot be fully or adequately classified as models at all. Such an algorithm 'will always exceed its name, its type, its genus, for it is immanently modifying itself through the world' (p.25). Because of the ways in which algorithms can be said to see, and also to seize the function of seeing, Amoore situates her studies 'within a genealogy of technologies of perception' (p. 15).

But algorithms are not merely technologies of perception. They also give accounts - of themselves, of us, of a different us, of more than one us. Drawing on an insight from Gilles Deleuze, Amoore builds the concluding chapter of the work around this narrative function, thinking through the ways in which algorithms 'engage in fabulation - they invent a people, write them into being as a curious body of correlated attributes, grouped into clusters derived from data that are themselves fabulatory devices' (p. 158). It is in this last chapter too that Amoore offers the most explicitly ethical formulation of her cloud ethics, concluding a work that is predominantly an archeology and an ontology of the algorithm. She insists it must be an ethic of critique and resistance that can arise only from within, and not outside, this regime of algorithmic reason:

The resistant orientation to attribution I have in mind does not stand outside or in opposition to the attributive power of the algorithm. In common with all other forms of resistance, this is an orientation that shares the same horizon as 
the mode of power. Indeed, I have explained in this book the extent to which human subjects dwell within the algorithm, as it comes into being also through relations with subjects and objects (pp. 170-171).

Amoore is most effective at communicating the sense in which machine-learning algorithms are neither human nor inhuman. They are hybrid. They are cyborgs. Like Donna Haraway and N. Katherine Hayles, whose works she frequently cites, Amoore contributes much to expand both the political vocabulary and the political imagination required to meet new ambient conditions of knowledge, agency, and governance established by the convolutional neural network, the random forest tree, the deep learning algorithm, and other fiefdoms in an expanding kingdom of automated reason and decision-making. In the spirit of Jacques Derrida, offered either as hyperbole or perhaps as an omen, Amoore asserts, more than once, that there is nothing outside the algorithm.

Publisher's Note Springer Nature remains neutral with regard to jurisdictional claims in published maps and institutional affiliations.

Paul Lewis

University of the Incarnate Word, San Antonio, TX 78209, USA lewis@uiwtx.edu 